http://jmscr.igmpublication.org/home/ ISSN (e)-2347-176x ISSN (p) 2455-0450

crossref DOI: https://dx.doi.org/10.18535/jmscr/v9i12.17

\title{
Carcinosarcoma of Ovary with Ileal Metastasis: A Diagnostic Dilemma
}

\author{
Authors \\ Dr Supriya Verma ${ }^{1}$, Dr Sarita Asotra ${ }^{2 *}$, Dr Abhilash Singh ${ }^{3}$, Dr V Anish Chandran ${ }^{4}$, \\ Dr UK Chandel ${ }^{5}$, Dr Neeti Aggarwal ${ }^{6}$ \\ ${ }^{1}$ Senior Resident, Department of Pathology, Indira Gandhi Medical College, Shimla \\ ${ }^{2}$ Associate Professor, Department of Pathology, Indira Gandhi Medical College, Shimla \\ ${ }^{3,4}$ Junior Resident, Department of Pathology, Indira Gandhi Medical College, Shimla \\ ${ }^{5}$ Professor, Department of Surgery, Indira Gandhi Medical College, Shimla \\ ${ }^{6}$ Professor, Department of Radiology, Indira Gandhi Medical College, Shimla \\ *Corresponding Author \\ Dr Sarita Asotra
}

\begin{abstract}
Ovarian carcinosarcomas are rare gynecological malignancies, accounting for less than $1 \%$ of all ovarian tumors. They are characterized by containing both high grade, malignant epithelial and mesenchymal componants The unusual histology can represent a challenge both in terms of diagnosis and treatment. We present a case of ovarian carcinosarcoma with illeal metastasis presenting as intestinal obstruction.

Keywords: Carcinosarcoma, Ovary, Illeum.
\end{abstract}

\section{Introduction}

Ovarian carcinosarcoma is rare and is responsible for less than $1 \%$ of all ovarian neoplasms ${ }^{(1)}$. Apart from ovary, it can occur in other organs of the genito-urinary tract, including uterus, fallopian tubes, breast, and urethra. The uniqueness of this rare malignancy is that it is a biphasic tumour that involves both epithelial and mesenchymal components of the affected organ. Particularly in the ovary, the epithelial component may be endometrioid, clear cell, serous or squamous epithelium. The mesenchymal component may be homologous comprising of areas showing features of fibrosarcoma and leiomyosarcoma or heterologous showing areas of osteosarcoma, rhabdomyosarcoma, liposarcoma or chondrosarcoma differentiation ${ }^{(2)}$.
The contribution of each element in the development of the malignancy varies and for this reason, the preoperative diagnosis of the disease cannot be reliably made by core biopsy or Fine Needle Aspiration Cytology. Histopathological examination is the only method for diagnosing carcinosarcoma. Ovarian carcinosarcoma occur more frequently in postmenopausal women and generally have a highly aggressive behaviour and overall poor prognosis.

\section{Case Report}

A 48 year old female presented with complaint of pain in the lower abdomen and heaviness since 6 years. Contrast enhanced computed tomography (CECT) revealed peripherally enhancing heterogenousmass in lower abdomen 
communicating with the ilealloops andabutting sigmoid colon with loss of fat plane at fundus and body of uterus (Figure 1A and 1B) .Surgical resection of the mass was done. We received specimen of uterus with bilateral adnexa, adherent ileal loop and ileo-mesenteric lymph nodes for histopathological examination (Figure 2).Uterus was seen adherent to an ovarian mass on one side measuring $6 \times 6 \times 3 \mathrm{~cm}$. The mass was seen invading uterine serosa and occupying outer half of myometrium. The ovarian mass was globular and bosselated and showed grey to tan brown areas with necrotic foci on cut section. Ileal loop was adherent to the ovarian mass. Cut section of ileum revealed growth extending upto serosa.

Microscopic examination of paraffin sections from ovarian mass showed biphasic tumour revealing both carcinomatous (epithelial) and sarcomatous components. Carcinomatous component was comprised of tumour epithelial cells arranged in glands, cords and sheets and show moderate pleomorphism, high nuclear to cytoplasmic ratio, vesicular chromatin, conspicuous nucleoli and moderate amount of eosinophilic cytoplasm. Amidst the epithelial component, sarcomatous component showed pleomorphic spindle cells with marked cytological atypia (Figure 3 and Figure 4). Mitotic activity was brisk. In addition, tumour giant cells, inflammatory cell infiltrate and marked areas of necrosis were also seen. Lymphovascular and perineural invasion were present. Myometrium showed tumour deposits and lymphovascular emboli. Sections from ileum showed same biphasic tumour cells infiltrating serosa and reaching upto mucosa (Figure 5 and Figure 6). Based on above histopathological features, diagnosis of carcinosarcoma of ovary with homologous sarcomatous component andileal metastasis was made. Immunohistochemistry showed positivity for cytokeratin and vimentin and hence the diagnosis was confirmed.

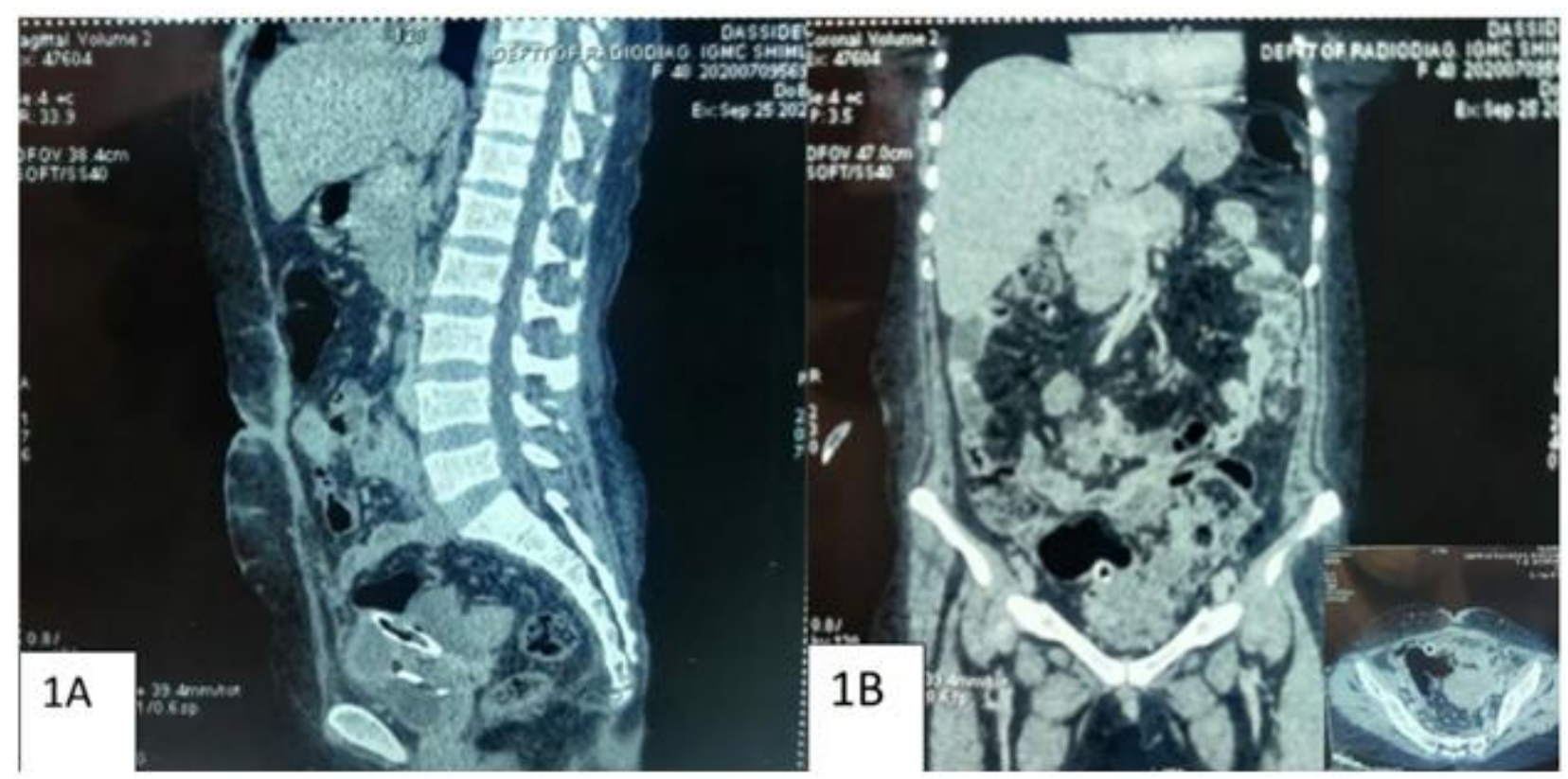

Figure 1A and 1B: Contrast enhanced computed tomography (CECT) revealing heterogenous mass in lower abdomen communicating with the ileal loops 


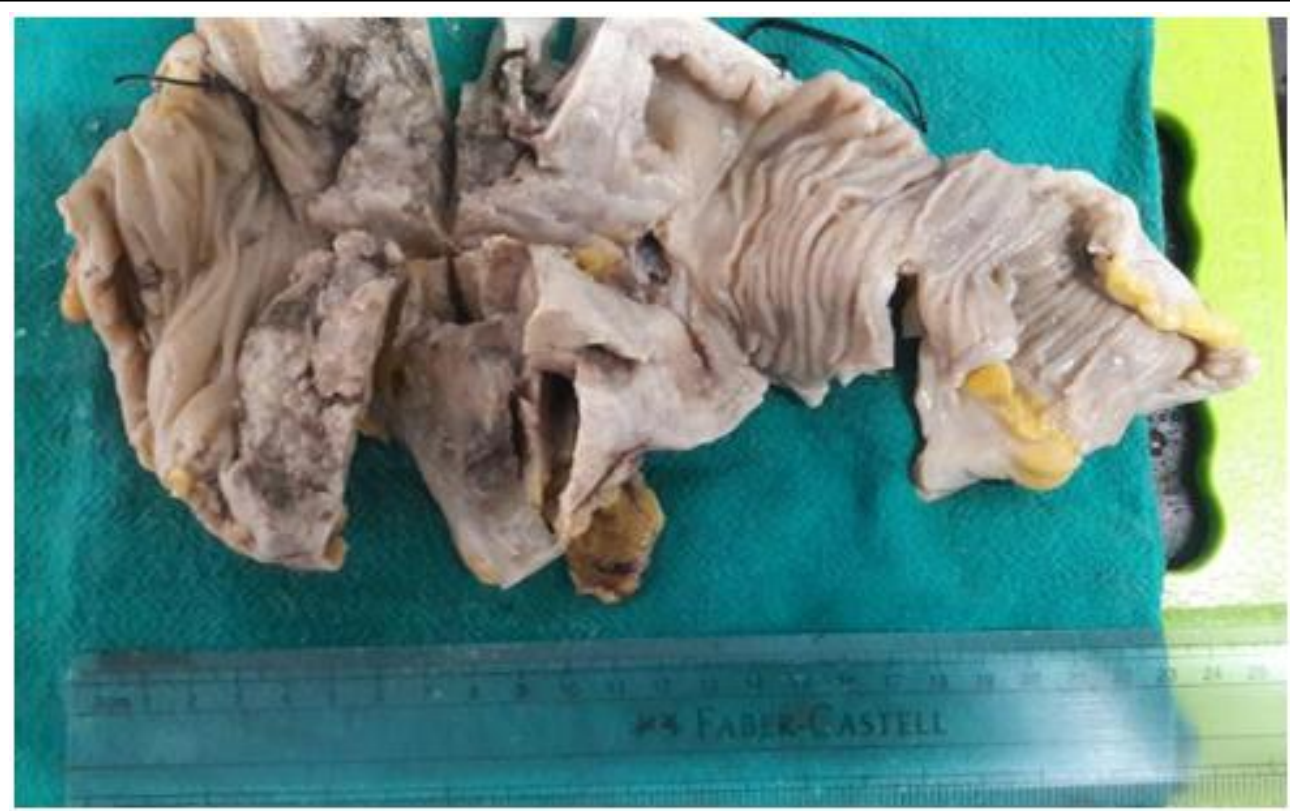

Figure 2: Gross photograph showing specimen of one sided ovarian mass with adherent ileal segment

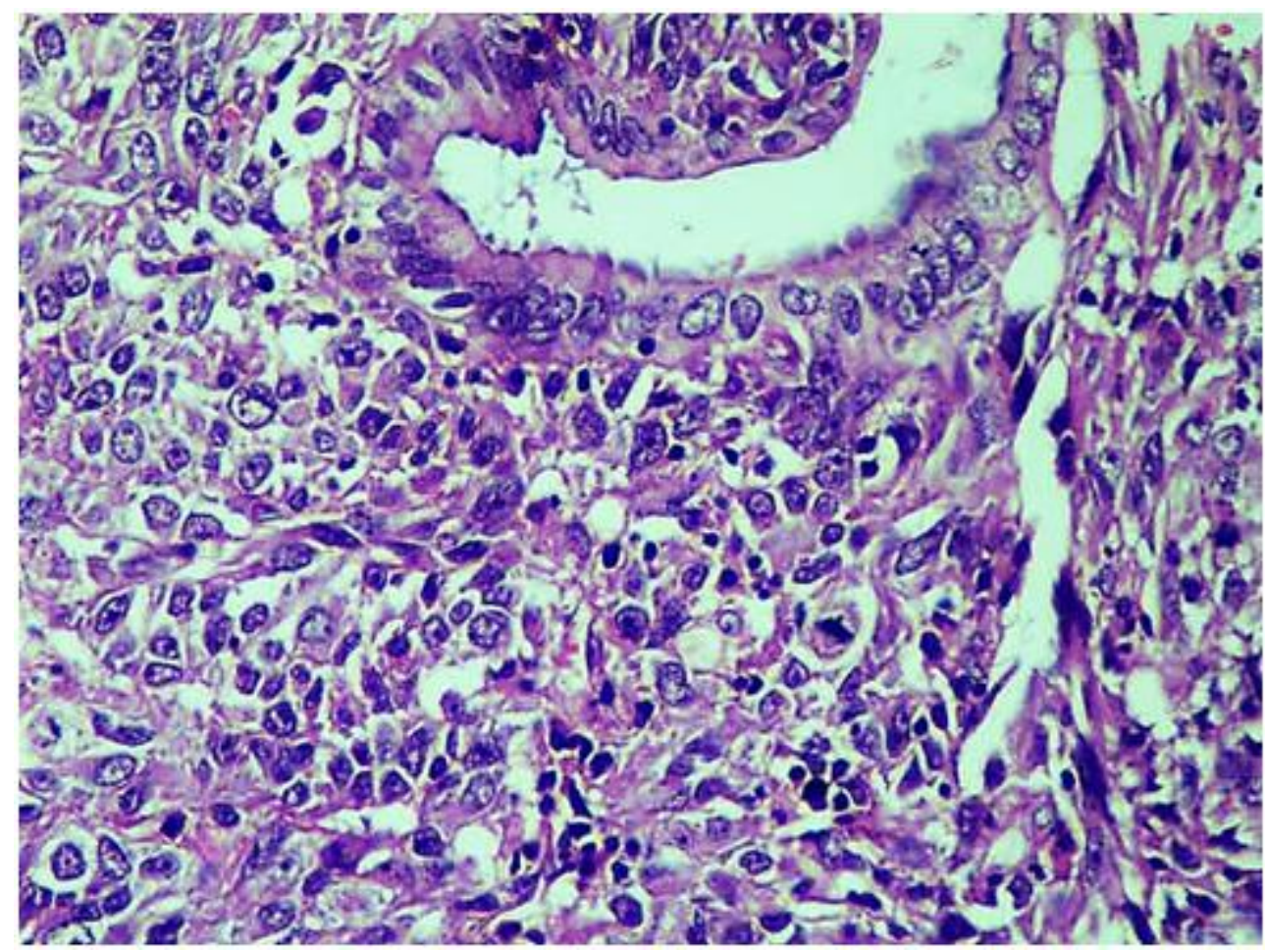

Figure 3: Photomicrograph of ovarian mass showing biphasic tumor revealing carcinomatous and sarcomatous component (H\&E, 400X) 


\section{JMSCR Vol||09||Issue||12||Page 93-99||December}

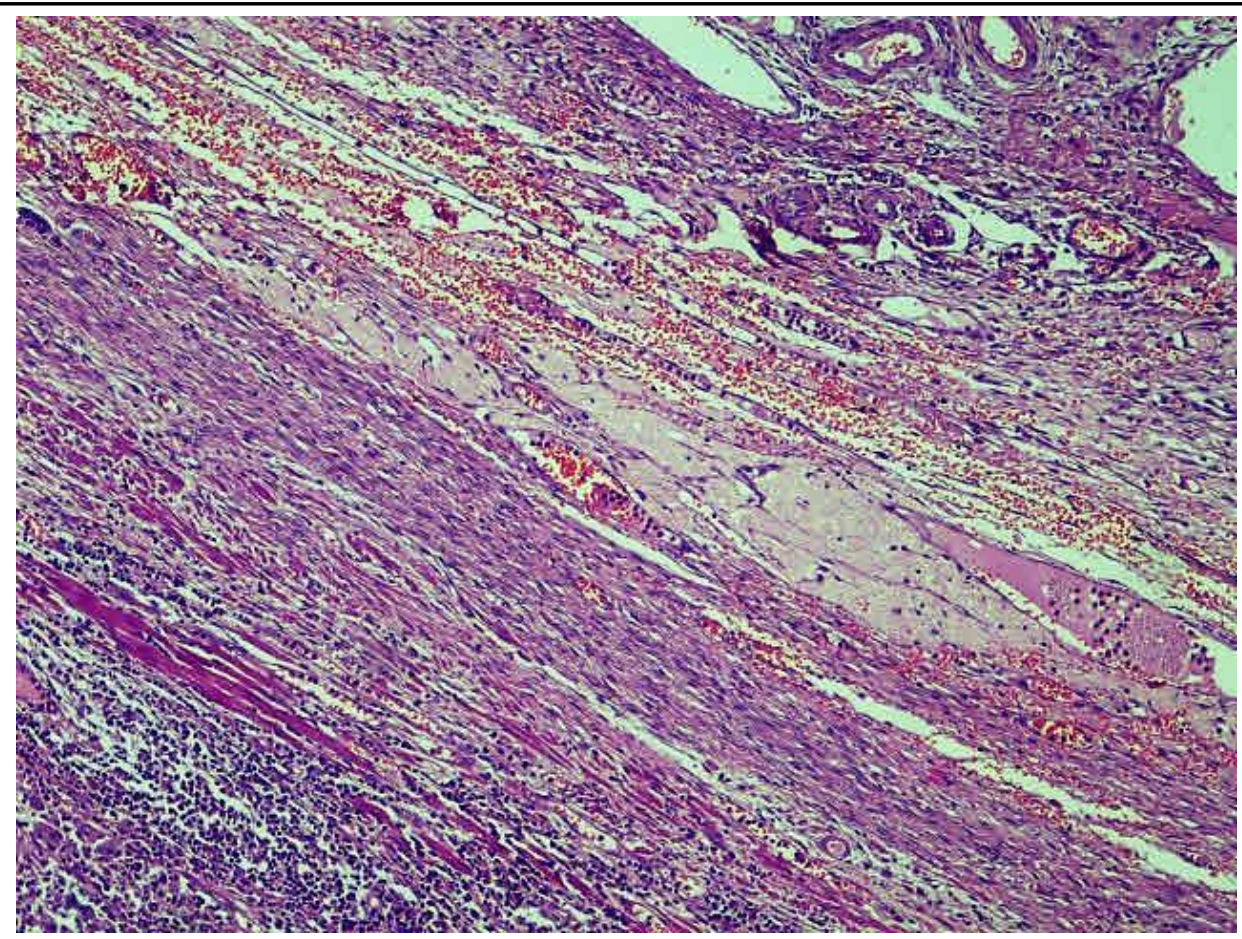

Figure 4: Photomicrograph showing small focus of tumour with adjacent normal ovarian stroma (H\&E, 100X)

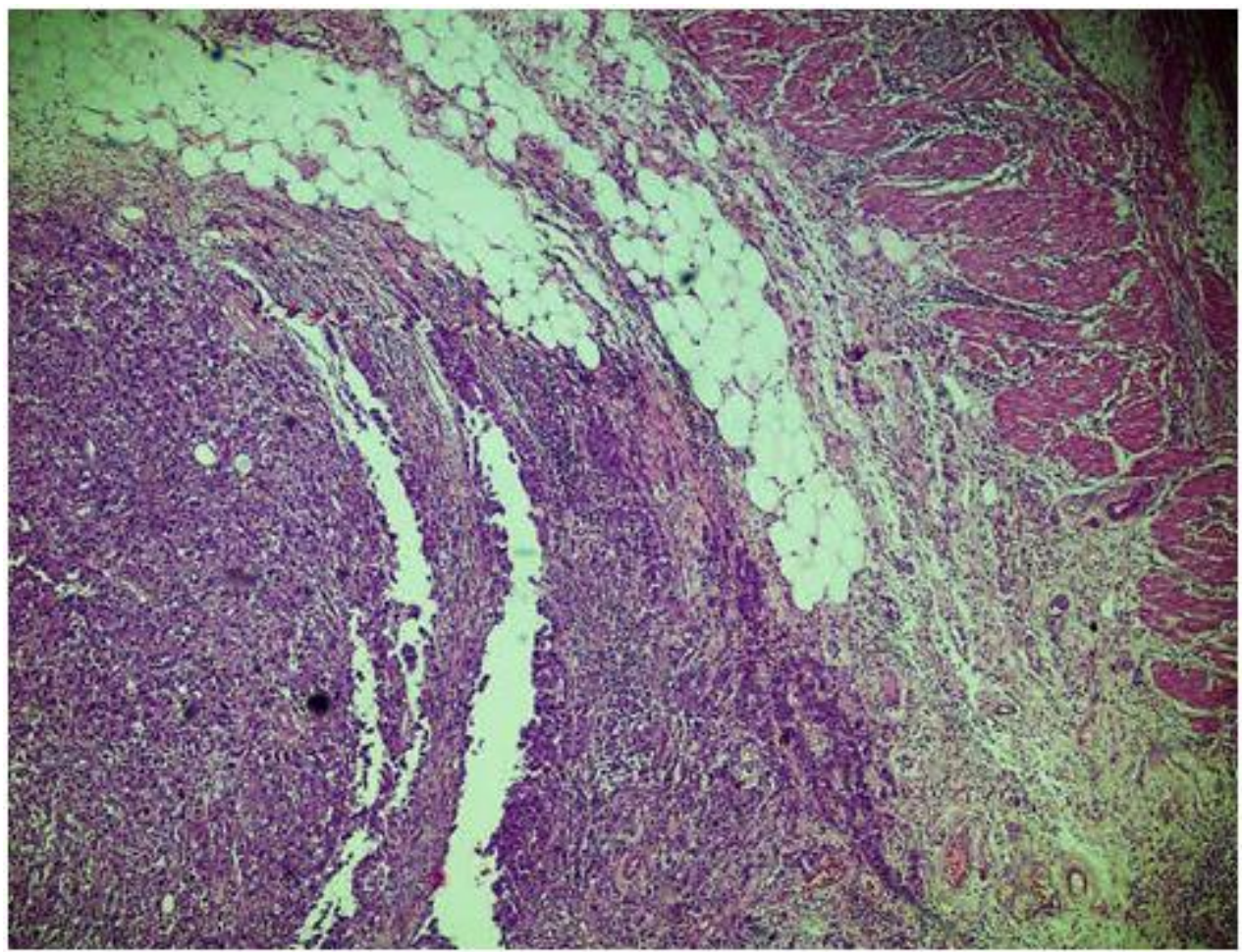

Figure 5: Photomicrograph of ileal mass showing sheets and cords of tumor epithelial cells infiltrating serosa \& muscularis propria (H\&E, 100X) 


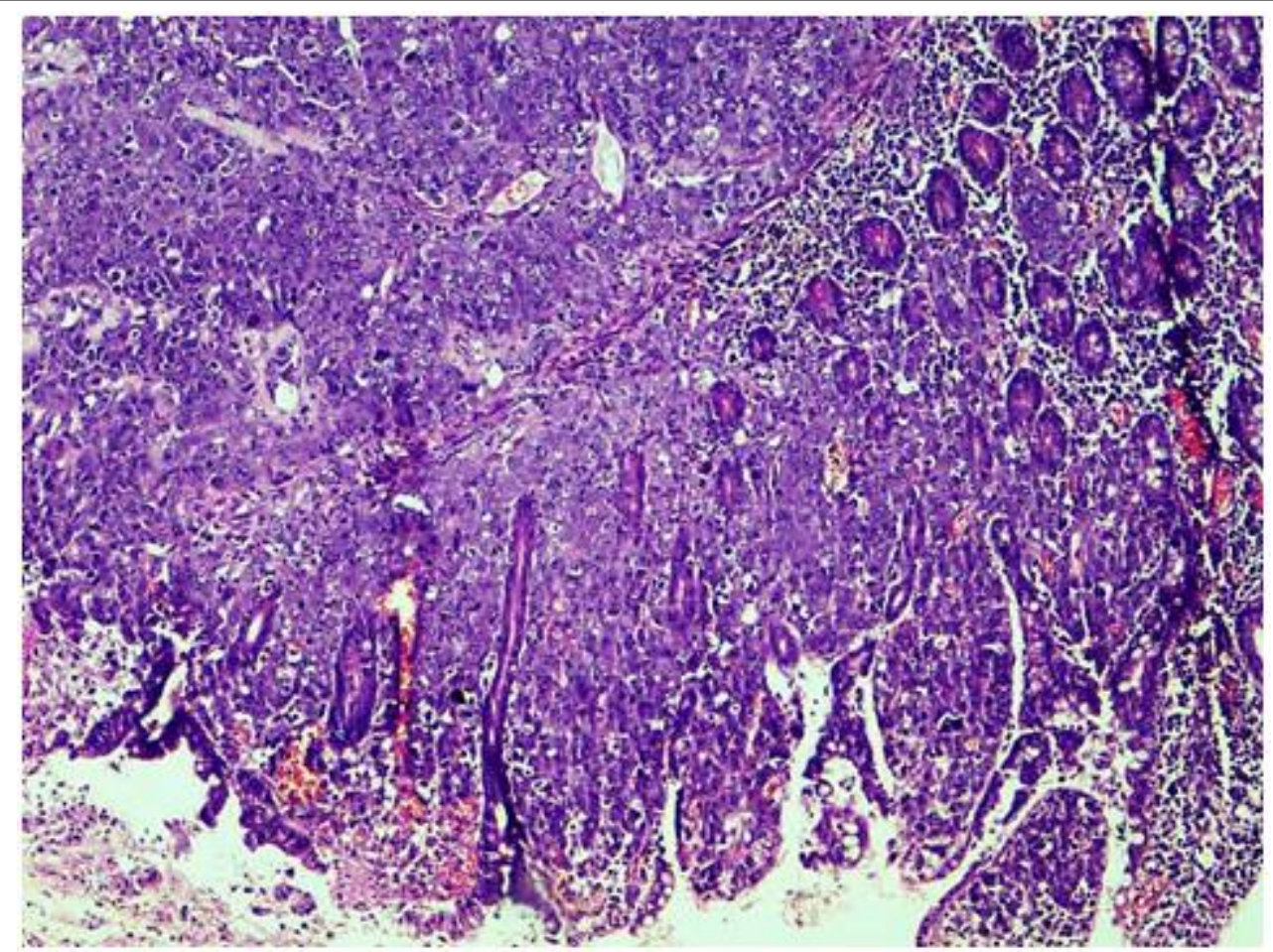

Figure 6: Photomicrograph of ileal mass showing sheets and cords of tumor epithelial cells infiltrating submucosa \& mucosa (H\&E, 100X)

\section{Discussion}

Malignant mixed mullerian tumour (MMMT) or carcinosarcoma of the ovary are rare neoplasms associated with an aggressive outcome and overall poor prognosis. The results of previous studies have demonstrated that the majority of patients with MMMT of the ovary are Caucasian and were very advanced at the time of surgery ${ }^{(3)}$.

Carcinosarcomas are rare tumours and histologically shows combination of malignant epithelial and malignant mesenchymal components. They can occur throughout the female genital tract but are most common in the uterus. Carcinosarcoma of the ovary is very rare and account for only <1-2\% of all malignant ovarian tumours. As such, not much literature is available on their behavior and management ${ }^{(4)}$.

Grossly, the tumours are solid or cystic, fleshy and hemorrhagic. It frequently spreads beyond the ovary and over peritoneal surfaces at the time of surgery. It is the epithelial component which metastasizes usually. The carcinomatous component may be of serous, endometrioid, clear cell, or squamous types. The malignant mesenchymal component of the tumour is described to be heterologous or homologous depending on the origin of its mesenchymal tissue. Heterologous elements are tissues which are not normally found in the ovary, eg, cartilage, bone, smooth or striated muscle and adipose tissue. If sarcomatous component comprises of elements that are native to the ovary like endometrial stromal sarcoma, fibrosarcoma or leiomyosarcoma, then it is described as homologous $^{(5)}$. It has been suggested that heterologous tumours may be more advanced and have a worse prognosis ${ }^{(6)}$. Our case had homologous sarcomatous component with ileal metastasis imparting bad prognosis.

Most common age group for manifesting ovarian carcinosarcoma is between sixty to seventy years.It occurs most commonly in postmenopausal women of low parity ${ }^{(7)}$. The most common symptoms include abdominal pain, distention, nausea, vomiting and weight loss.

The pathogenesis of ovarian carcinosarcoma is a topic of debate. The combination theory states that the two components of the tumor originate from a common epithelial stem cell which has undergone metaplastic change to a sarcomatous form in some 
areas of malignant tissue whereas the collision theory states that they are of different origin.Few reports suggest thatthere is an association between ovarian carcinosarcomas and pelvic irradiation ${ }^{(8)}$.

The stage classification used for carcinosarcoma of ovary is same as FIGO (International Federation of Gynecology and Obstetrics) system that is applied to other ovarian adenocarcinomas. FIGO staging at the time of diagnosis is commonly stage III and IV. Almost all patients will be expressing the antigen CA-125 (Cancer antigen -125$)$ at a value above $75 \mathrm{U} / \mathrm{ml}^{(9)}$.

Because of the rarity of the disease, no standard treatment has been developed. Data show that maximal cytoreduction correlates with better progression-free and overall survival in carcinosarcoma, and complete cytoreduction should be the goal of surgical treatment. Adjuvant chemotherapy should be given in pathological Stage I-IV disease, and the chemotherapy regimens are same as in epithelial ovarian cancer. Platinum-based chemotherapy is the key drug for ovarian carcinosarcoma. However, carcinosarcoma has poor response to chemotherapy having response rates of about $20 \%{ }^{[10]}$. The high rate of recurrence of carcinosarcoma of the ovary treated with platinum-based regimens, however, suggests that this alone is insufficient.

Negative prognostic factorsin the course of the disease include overriding sarcomatoid element more than $25 \%$ and especially the heterologous one, disease stage, tumor grade, large size of the initial tumor and residual disease ${ }^{[11]}$.

In comparison with other ovarian carcinomas, the response to therapy and overall survival is poor. Median survival is $4-14$ months.

\section{Conclusion}

Ovarian carcinosarcoma is an extremely uncommon tumor of female genital tract with an aggressive and lethal clinical course. It is extremely rare and represents $1 \%$ of all malignant ovarian tumours. It usually presents in advanced stages and prognosis in most cases is extremely poor. Such cases must be meticulously recorded for future reference with regard to the treatment provided and outcome achieved.

\section{References}

1. Del Carmen MG, Birrer M, Schorge JO. Carcinosarcoma of the ovary: a review of the literature. Gynecol Oncol. 2012;125: 271-277.

2. Makris GM, Siristatidis C, Chrelias C. Ovarian carcinosarcoma: a case report, diagnosis, treatment and literature review. Hippokratia.2015; 3:256-259.

3. Harris MA, Delap LM, Jayson GC. Carcinosarcoma of the ovary.Br J Cancer. 2003 ;5: 654-657.

4. Muntz HG, Jones MA, Goff BA, Fuller AF, Jr., Ni-krui N, Rice LW, Tarraza HM. Malignant mixed mulleriantumors of the ovary: experience with surgical cytoreduction and combination chemotherapy. Cancer 1995;7:1209-1213.

5. Pushpagiri N, Dinakaran S, Chidambaram A, Pari P. Carcinosarcoma of ovarya rare case report and literature overview. International Journal of Advances in Medicine. 2017;3:440-442.

6. Brown E, Stewart M, Rye T, Al- Nafussi A, Williams AR, Bradburn $\mathrm{M}$, et al. Carcinosarcoma of the ovary: 19 years of prospective data from a single center. Cancer 2004;10:2148- 53.

7. Dasgupta S, Bose D, Bhattacharyya NK, Biswas PK. Carcinosarcoma of ovary with its various immunohistochemical expression: Report of a rare case. J Cancer Res \& Therapeutics 2015;4:1034-1036.

8. George EM, Herzog TJ, Neugut AI, Lu YS, Burke WM, Lewin SN, et al. Carcinosarcoma of the ovary: natural history, patterns of treatment, and outcome. Gynecol Oncol. 2013;131:4245.

9. Sood AK, Sorosky JI, Gelder MS, Buller $\mathrm{RE}$, Anderson B, Wilkinson EJ, et al. 
Primary ovarian sarcoma: analysis of prognostic variables and the role of surgical cytoreduction. Cancer. 1998;82: 1731-1737.

10. Priyadarshini P, Majumdar SK, ParidaDK. Carcinosarcoma of ovary with long-term overall survival. Oncol J India 2019;3:4414.

11. Rauh-Hain JA, Shoni M, Schorge JO, Goodman A, Horowitz NS, Del Carmen MG. Prognostic determinants in patients with uterine and ovarian carcinosarcoma. J Reprod Med 2013;58:29-304. 